\title{
Vaccination Coverage of Infants and Young Children in a Selected Rural area of Mymensingh
}

\begin{abstract}
This study was conducted to estimate vaccination coverage of infant and young children in a selected rural area of Mymensingh. This was done on the background that vaccine preventable diseases are major causes of under-5 mortality and morbidity in Bangladesh. Though EPI coverage in Bangladesh is high still there are reported cases of meningitis, pneumonia and measles. This was a community-based cross-sectional descriptive study conducted among 240 children belonging from birth to 24 months age group from Churkhai village of Bhavokhali union, Sadar Mymensingh during January 2019 as a part of Residential Field Site Training of 3rd year students under the guidance of Department of Community Medicine of Community Based Medical College Bangladesh. The sampling technique was purposive. A pre-designed, pre-tested questionnaire has been used to collect required information by face to face interviewing mothers of infant and young child with verification of immunization card. Out of total children between birth to 24 months age group surveyed, 121 $(50.42 \%)$ were males and 119 (49.58\%) were females. Most of them 217 (90.42\%) were fully immunized and $23(9.58 \%)$ were partially immunized. BCG vaccination was $100 \%$ though 19 $(7.92 \%)$ were 2 months late. Pentavalent, PCV, b OPV, f IPV vaccination coverage was $92.89 \%$ each, though 5 (2.37\%) were 2 months late. Measles-Rubella coverage was $83.04 \%$. Vaccination coverage was better than the finding of other studies in Bangladesh and neighboring countries except Measles-Rubella coverage. We should motivate mothers to attain a full vaccination coverage of $100 \%$.
\end{abstract}

Dipu $\mathrm{SS}^{1}$, Hossain $\mathrm{MT}^{2}$

CBMJ 2020 January: vol. 09 no. 01 P: 19-24

Key words: Vaccination coverage, Infants and Young Children, Rural Area, Mymensingh.

\section{Introduction}

Vaccination is a preventive measure which provides specific protection against diseases. In Bangladesh it is provided by Expanded Program on Immunization (EPI) service. Target groups of immunization are infant and young child and women of reproductive age group. We have surveyed on vaccination coverage of infant and young child by taking interview of mothers and checking EPI cards and assessed factors influencing vaccination status. Infant is a young baby from birth to 12 months of age. Infants include new born (first 28 days of life) and post-neonatal period. Young child is from 12 months to 24 months. ${ }^{1-}$ 5 Vaccine preventable EPI diseases in Bangladesh are tuberculosis, poliomyelitis, diphtheria, pertussis, tetanus, hepatitis $B$, Hemophilus influenzae type $B$, pneumococcal pneumonia, measles and German measles. Immunization against tetanus is provided mainly by Tetanus Toxoid immunization among women of reproductive age group. $^{3,5,6}$ In Bangladesh, 92\% babies are protected from neonatal tetanus. Tetanus vaccination is also incorporated in pentavalent vaccine given in infancy. BCG (Bacillus Calmette Guerin) covers for tuberculosis, pentavalent covers for diphtheria, pertussis, tetanus, hepatitis $B$, Hemophilus influenzae type B, Pneumococcal conjugate vaccine covers pneumonia due to pneumococcus, MR vaccine covers for measles and German measles. $^{6}$ Bangladesh has impressive gain on reducing neonatal mortality (year 1990: 54; 2000: 42; 2011: 32 and 2019: 19 ), infant mortality (year 1990: 100; 2000: 66; 2011: 43 and 2019: 26) and under-five mortality

1. Dr. Sultana Sobnam Dipu, Associate Professor, Community Medicine, CBMCB

2. Dr. Md. Tufael Hossain, Associate Professor, Community Medicine, CBMCB.

Address of correspondence:

E-mail: dr.dipuss12@gmail.com

Contact: 01714306011 
(year 1990: 144; 2000: 94; 2011: 53 and 2019: 30.8). ${ }^{7-10}$ And the credit goes to vaccination because most of the diseases in under- 5 population are vaccine preventable. Significant contributor of neonatal mortality is infection: neonatal sepsis, meningitis and tetanus. ${ }^{11}$ Significant contributor of infant mortality is infection: acute respiratory tract infections especially pneumonia, diarrheal diseases, neonatal sepsis, meningitis and tetanus. ${ }^{2-6}$ Significant contributor of under-five mortality is infection: pneumonia and diarrhea. ${ }^{2-6}$ Globally, these diseases account for $29 \%$ of all deaths of children less than 5 years of age. ${ }^{12}$ Bangladesh has impressive gain in vaccination coverage (year 1985: 2 percent; 1997: 56 percent and has achieved 90 percent coverage for all vaccines except inactivated poliovirus vaccine. ${ }^{13-21}$ Though efficacy of $B C G$ vaccine is not cent per percent; on average, BCG vaccine significantly reduces the risk of TB by $50 \%{ }^{22}$ EPI program keeps BCG vaccine primarily for prevention of neonatal meningitis, miliary tuberculosis and secondarily keeping in mind that there is high prevalence of tuberculosis in Bangladesh. The overall national TB prevalence estimates for all forms is 260 for Bangladesh. ${ }^{23}$ Polio causes acute flaccid paralysis leading to disability. Five of the six WHO regions- representing of the world's population are now free of the wild poliovirus. Only two countries worldwide continue to see wild poliovirus transmission: Pakistan and Afghanistan. ${ }^{24}$ Bangladesh was maintaining diphtheria free status for last 3 decades due to high vaccination coverage. There were 3608 probable cases and 241 laboratory confirmed cases in the diphtheria outbreak among the migrants from Myanmar who intruded in 2017-18 residing in the temporary settlements in Cox's Bazaar, Bangladesh. Nearly $68 \%$ of these cases were under 15 years of age while only $25.9 \%$ had been vaccinated against diphtheria. ${ }^{21}$ Pertussis, Hemophilus influenzae type B, pneumococcal pneumonia and measles contribute to $A R I$ and pneumonia. Measles contribute to diarrhea. ${ }^{2-6}$ Common causes of under-five morbidity are diarrhea, respiratory tract infection and pneumonia. As per a Bangladeshi study, the prevalence rates are 45 percent, 32 percent and 18 percent respectively. ${ }^{25}$ Timely vaccinations has role to prevent. $63 \%$ of population lives in rural area. ${ }^{26}$ Infant and young child constitutes more than half of under 5 children which is about $10 \%$ of population. $^{27,28}$ Studying rural population represents Bangladesh. Our survey area was Churkhai, a village of 12 Bhavokhali Union. It has 1,889 households with a population of 8,791 . $^{29}$

\section{Methods}

This was a cross-sectional descriptive study. Sample size was 240. Sample size and study area was selected purposively. The sample constituted infant and young child. Respondents were mothers of infant and young child. Data were collected on a predesigned questionnaire by face to face interviewing respondents and verification of immunization card. The data were entered and analyzed by SPSS version 16.0.

\section{Results}

240 mothers who had one child aged between newborn to 24 months participated in the study. The age of children ranged from newborn to 24 months. Mean age was 12.06 months with a standard deviation of \pm 6.868 months. Proportion of children belonging to less than 6 months $69 \quad(28.75 \%)$ was predominant. Boys 121(50.42\%) were marginally higher than girls $119(49.58 \%)$. Male: Female ratio was 101.68: 100.

Table I: Age and sex distribution of infants and young children $(n=240)$

\begin{tabular}{|c|c|c|c|}
\hline \multirow{2}{*}{ Age in months } & \multicolumn{2}{|c|}{ Sex } & \multirow{2}{*}{ Total } \\
\cline { 2 - 3 } & Male & Female & \\
\hline Less than 6 months & $34(14.17 \%)$ & $35(14.58 \%)$ & $69(28.75 \%)$ \\
\hline 7 to 12 months & $28(11.67 \%)$ & $35(14.58 \%)$ & $63(26.25 \%)$ \\
\hline 13 to 18 months & $34(14.17 \%)$ & $19(7.92 \%)$ & $53(22.08 \%)$ \\
\hline 19 to 24 months & $25(10.42 \%)$ & $30(12.50 \%)$ & $55(22.92 \%)$ \\
\hline Total & $121(50.42 \%)$ & $119(49.58 \%)$ & $240(100.00 \%)$ \\
\hline
\end{tabular}


Age of mothers ranged from 17 yrs to $35 \mathrm{yrs;}$ mean age $23.60 \mathrm{yrs}$ and standard deviation $4.238 \mathrm{yrs}$. Most of the mothers belonged to age group 18 years to 29 years 195 (81.25\%), literate 202 (84.17\%), housewife 227(94.58\%), belonged to middle class family $122(50.83 \%)$. Number of children per family was 1.95. Respondent mothers had 469 offspring. About half of the children $122(51.17 \%$ ) were infant and young children. Exclusive breastfeeding was 208 (86.67\%) and breast feeding continued up to the age $132(77.19 \%)$. Vaccination coverage was $100 \%$; full vaccination $217(90.42 \%)$ and partial vaccination 23 (9.58\%).

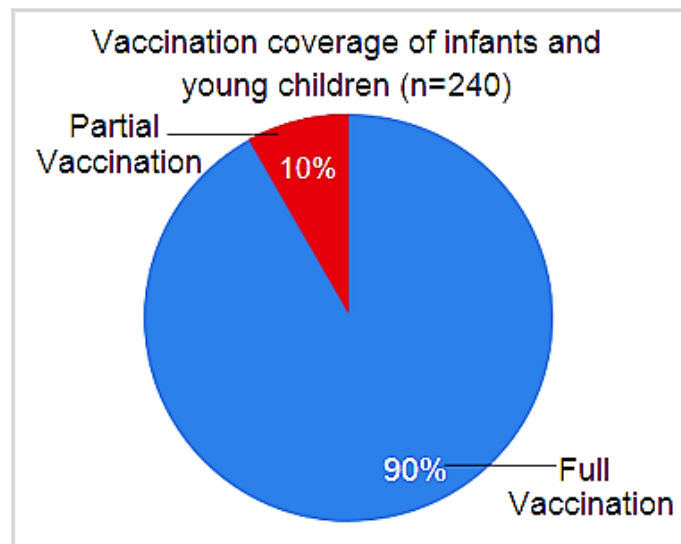

Figure 1: Pie Chart showing vaccination coverage of infant and young children.

BCG vaccination was $100 \%$ though 19 (7.92\%) were 2 months late. Pentavalent, PCV, OPV, IPV vaccination coverage was $92.89 \%$ each, though 5 (2.37\%) were 2 months late. Measles-Rubella coverage was $83.04 \%$. Prevalence of partial vaccination was $9.58 \%$. Prevalence of partial vaccination was higher among illiterate (10.53\%), poor $(10.71 \%)$ and having more than 2 children (10\%). Most of infants and young children229 $(95.42 \%)$ were in healthy status. Those who had disease (10 cases of pneumonia and 1 case of measles) were preventable by EPI vaccines. Prevalence of EPI preventable diseases was 11 (4.58\%).
Table II: Distribution of EPI preventable diseases among infants and young children $(n=240)$

\begin{tabular}{|l|c|c|}
\hline Status & Frequency & Percentage \\
\hline EPI preventable diseases & 11 & 4.58 \\
\hline Healthy status & 229 & 95.42 \\
\hline Total & 240 & 100.00 \\
\hline
\end{tabular}

EPI preventable disease was absent in fully vaccinated children. The prevalence was 11 $(47.83 \%)$ among partially vaccinated infant and young child.

\section{Discussion}

The sample constituted infant and young child. Information about the sample was gathered from mothers of reproductive age group who have a child from newborn to 24 months. Children belonging to less than 6 months $(28.75 \%)$ was predominant and male: female ratio 101.68: 100. Mean with standard deviation of mothers was 23.60 years with 4.238. Most of the mothers belonged to age group 18 to 29 yrs. In an Indian 2010 study, females $(52.85 \%)$ were more than males $(47.15 \%){ }^{30}$ In several other Indian studies males (53. 8 percent, 59.7 percent and 56.46 percent respectively) were more than females (46.2 percent, 40.3 percent and 43.54 percent respectively. ${ }^{31-33}$

In this study, vaccination coverage was $100 \%$. $217 / 240(90.42 \%)$ were fully immunized and $23 / 240$ (9.58\%) were partially immunized. BCG vaccination was $100 \%$ though $(19 / 240)$ (7.92\%) were 2 months late. Pentavalent, PCV, OPV, IPV vaccination coverage was $92.89 \%$ each, though (5/211) (2.37\%) were 2 months late. Measles-Rubella coverage was $83.04 \%$. Prevalence of partial vaccination was $9.58 \%$. Prevalence of partial vaccination was higher among illiterate (10.53\%), poor $(10.71 \%)$ and having more than 2 children (10\%) and female child (10.08\%). Vaccination coverage of this study is better than global routine vaccination coverage which are DPT 3 doses $85 \%$, Hepatitis B 3 doses $43 \%$, Hemophilus influenzae type B 3 doses $72 \%$, Oral polio 3 doses $86 \%$, PCV 3 
doses $48 \%$, Measles vaccine $71 \%$ and Rubella vaccine $71 \%{ }^{34}$ Vaccination coverage of this study is similar to national and regional data. Bangladesh, Bhutan, DPR Korea, Maldives, Nepal, Sri Lanka and Thailand have achieved $90 \%$ or more national coverage with DPT 3 doses in 2017. Of these, Maldives and Sri Lanka have achieved $90 \%$ coverage for all vaccines given during infancy and the remaining 5 countries have achieved 90\% coverage for all vaccines except inactivated poliovirus vaccine. Myanmar, India, Indonesia and Eat-Timor are lagging behind. ${ }^{21}$ As per BDHS 2017-18 data $89.1 \%$ of infant and young child are fully vaccinated. Coverage for BCG 98.3\%, pentavalent 3 doses 95.9\%, Oral Polio 3 doses $94.5 \%$ and Measles vaccine 91\%. ${ }^{35}$ PCV 3 doses $95 \%$ and Measles Rubella coverage was $87.50 \%{ }^{6}$

Vaccination coverage of this study is better than other studies conducted in Bangladesh from 1995 to till date. In a study conducted from 1995 to 1997, full vaccination ranged from $58 \%$ to $78 \%$. Vaccination was high for BCG ranging from 91.7 percent to 98.8 percent and low for measles ranging from 60 percent to 77.8 percent. $^{36}$ In 2002 study, full vaccination was $60 \%$. Vaccination for BCG $97 \%$, DPT 3 doses $75 \%$ and measles $67 \%{ }^{37}$ In 2014 study, full vaccination was $83 \%$, BCG 97\%, OPV 3 doses $92 \%$, pentavalent 3 doses $91 \%$ and measles vaccine $85 \%$. Children who were in the lowest wealth quintile, who had mothers without antenatal care visits, or who had mothers without autonomy in healthcare decision-making were less likely to be fully vaccinated. $^{38}$

Vaccination coverage of this study was similar to an Indian study conducted in Tripura in 2013-14: full vaccination $90.9 \%$, partial vaccination $8.8 \%$ and non-immunized $0.3 \%$. BCG coverage was $99.7 \%$, measles $95.45 \%$, DPT and OPV $97.3 \%$ and HBV $95.45 \%$. Gender had no influence on vaccination. There was no gender difference between the children who are not fully immunized. ${ }^{32}$

Vaccination coverage was better than other studies conducted in different regions of India from 2005 to 2012: full immunization ranging from 25.1 to 86.67 percent. $^{30,31,33,38,39}$ In 2005 study, illiterate mother, Muslim religion, scheduled caste or tribes and higher birth order were significant predictors of partial immunized status of the child while those associated with the unimmunized status of the child were low socioeconomic status, Muslim religion, higher birth order, home delivery and belonging to a joint family. ${ }^{36}$ In 2009 study female children were more disadvantaged in terms of vaccination. ${ }^{33}$ In 2010 study the proportion of fully immunized children was higher in males (68.69\%) than in females (55.86\%). Most common reason (50\%) for partial and non-immunization of children was found to be ignorance on the part of parents. Education of parents was found to be significantly associated with immunization status. ${ }^{30}$ In 2011 study the proportion of fully immunized children was marginally higher in males $(87.61 \%)$ than in females $(85.55 \%) .{ }^{31}$ In 2012 study the major reasons for failure of immunization were postponing it until another time, child being ill and hence not brought to the centre for immunization, unaware of the need of immunization, place of immunization being too far, no faith in immunization, unaware of the need to return for 2nd and 3rd dose, mother being too busy, fear of side reactions, wrong ideas about immunization, and polio was considered only vaccine, and others. $^{37}$ In 2009 study coverage for BCG $75.1 \%$, DPT 3 doses $48.6 \%$, OPV 3 doses $47.9 \%$ and measles $29.9 \% .^{33}$ In 2010 coverage for BCG $92.86 \%$, OPV 3 doses $65.72 \%$, DPT 3 doses $65.72 \%$ and measles $62.38 \% .^{30}$ In 2011 coverage for BCG $98.5 \%$, Oral polio 3 doses $95.24 \%$, DPT 3 doses $92.38 \%$, Measles $87.62 \%$ and Hepatitis B 3 doses $84.76 \%$. $^{31}$

\section{Conclusion}

Infectious diseases are a major cause of morbidity and mortality in children. One of the cost-effective and easy methods for the wellbeing of a child is immunization. Though there is impressive gain on immunization 
coverage, still there are reported cases of meningitis, pneumonia and measles in our country. In this study though vaccination coverage against other diseases excellent but the measles rubella coverage was not up to the mark. We should motivate mothers to have $100 \%$ full vaccination coverage.

\section{References:}

1. Kliegman, Stanton, St Geme, Schor; Nelson Textbook of Pediatrics. First South Asia Edition. Elsevier 2016. Vol-1, Part II, Growth, Development and Behavior, Chapter 9, The Newborn,Chapter 10, The First Year, Chapter 11, The Second Year. Pages 62-76.

2. Gupte S. The Short Textbook of Pediatrics. 12th Edition. Jaypee Brothers Medical Publishers; 2016. Chapter 3, Normal Growth; P. 38-65.

3. Khan MR, Rahman ME. Essence of Pediatrics. 4th Edition. Elsevier; 2011. Chapter 2. Neonatology; Chapter 4, Growth and Development. Pages 7- 48, 56- 71.

4. Park K-Park's Textbook of Preventive and Social Medicine, Twenty-Fourth Edition, M/S Banarsida'sBhanot Publishers 1167, Prem Nagar, Jabalpur, 482001 (India) 2017. Chapter 9, Preventive Medicine in Obstetrics, Pediatrics and Geriatrics, Infant, Page 566.

5. Rashid KM, Rahman M, Hyder S, Rashid, Khabir, Hyder's Textbook of Community Medicine and Public Health, Reprinted Fourth Edition 2008RHM Publishers. Chapter VII- $\mathrm{MCH}$ and Reproductive Health. Child Health Care. Page 149- 155.

6. Mollah MAH, Nahar N. Step on to Pediatrics. 5th Edition, September 2020, Chapter 6, Childhood immunization \& Vaccine preventable diseases. Pages 23- 41.

7. Bangladesh Demographic and Health Survey 1990, Mitra and Associates; National Institute of Population Research and Training (NIPORT), Access date 7 November 2020.

8. Bangladesh Demographic and Health Survey 1999-2000, Mitra and Associates; National Institute of Population Research and Training (NIPORT), Access date 7 November 2020
9. Bangladesh Demographic and Health Survey 2011. Mitra and Associates; National Institute of Population Research and Training (NIPORT), Access date 7 November 2020

10. UNICEF, Bangladesh (BGD) - Demographic, Health and Infant mortality. https://data.unicef.org/country/bgd/ Access date 7 November 2020

11. UNICEF for every child. Maternal and Newborn Health disparities Bangladesh file:///C:/Users/mmc/AppData/Local/Temp/cou ntry\%20profile_BGD.pdf Access date 10 November 2020

12. World Health Organization, UNICEF. Executive Summary. Ending preventable child deaths from pneumonia and Diarrhea by 2025. The Integrated Global Action Plan for Pneumonia and Diarrhea.

13. National coverage evaluation surveys. Bangladesh. Dhaka, Directorate General of Health Services, 1990.

14. National coverage evaluation surveys. Bangladesh. Dhaka, Directorate General of Health Services, 1991.

15. National coverage evaluation surveys. Bangladesh. Dhaka, Directorate General of Health Services, 1992.

16. National coverage evaluation surveys. Bangladesh. Dhaka, Directorate General of Health Services, 1993.

17. National coverage evaluation surveys. Bangladesh. Dhaka, Directorate General of Health Services, 1994.

18. National coverage evaluation surveys. Bangladesh. Dhaka, Directorate General of Health Services, 1995.

19. National coverage evaluation surveys. Bangladesh. Dhaka, Directorate General of Health Services, 1996.

20. National coverage evaluation surveys. Bangladesh. Dhaka, Directorate General of Health Services, 1997

21. World Health Organization, Regional Office for South-East Asia. Regional Immunization Technical Advisory Group Report of the Ninth Meeting. New Delhi, India, 17 to 20 July 2018 
22. Colditz GA, Brewer TF, Berkey CS, Wilson ME, Burdick E, Fineberg $H V$, and Mosteller F. Efficacy of BCG vaccine in the prevention of tuberculosis: meta-analysis of the published literature. Review published. 2014. University of York.

23. Neerak Kak et al. Strategic priorities for TB control in Bangladesh, Indonesia and the Philippines - comparative analysis of national TB prevalence surveys. BMC Public Health 20, Article number: 560 (2020).

24. World Health Organization. Global polio eradication initiative applauds WHO African region for wild polio-free certification. Access date 10 November 2020.

25. Debnath SC, Riaz BK, Islam Z, et al. Malnutrition and morbidity profile of under-five children: a cross-sectional scenario in a rural area of Bangladesh. MOJ Public Health. 2017; 5(6):223-227.

26. World Bank. Rural population (\% of total population) in Bangladesh. https://data.worldbank.org/indicator/sp.rur.totl.z $s$ Access date November 2, 2020.

27. http://www.bbs.gov.bd/site/page/ef4d67562685-485a-b707-aa2d96bd4c6c/-

28. National Institute of Population Research and Training (NIPORT), Mitra and Associates, and ICF International. 2016. Bangladesh Demographic and Health Survey 2014. Dhaka, Bangladesh, and Rockville, Maryland, USA.

29. NIPORT, Mitra and Associates, and ICF International. Community Report, Mymensingh Zila, June 2012, Population and Housing Census 2011 Bangladesh Bureau of Statistics, Statistics and Informatics Division, Ministry of Planning.

30. Chaudhary V, Kumar R, Agarwal VK, Joshi VK, Sharma $D$. Evaluation of Primary immunization coverage in an urban area of Bareilly city using Cluster Sampling Technique. NJIRM. 2010; 1:10-5.

31. Gupta et al. Immunization coverage in the rural area of Pune, Maharastra, using the 30 cluster sampling technique. Journal of Family Medicine and Primary Care. 2013; 2 (1): 50-4
32. Datta A, Mog C, Das S, Datta S. A crosssectional study to assess the immunization coverage and vaccine dropout rates among 12 to 23 months old children in a rural area of Tripura. International Journal of Medical Science and Public Health 2017; 6 (2): 394-397.

33. Sharma R, Desai VK and Kavishvar A. Assessment of Immunization status in the slums of Surat by 15 clusters Multi Indicators Cluster Survey Technique Indian J Community Med. 2009; 34 (2): 152-155.

34. World Health Organization. Immunization coverage. Access date 9 November 2020.

35. Bangladesh Demographic and Health Survey 2017-2018, Key Indicators. Access date November 2, 2020

36. Towfiq $Y$, Hoque $S \&$ Siddiqi M. Using lot quality assurance sampling to improve immunization coverage in Bangladesh. Bulletin of the World Health Organization. 2001; 79 (6): 501-505

37. Khan MNA et al. Vaccination coverage survey in Dhaka District. Bangladesh Med Res Council Bull. 2005; 31 (2): 46-53

38. Mathew $L$ Boulton et al. Socioeconomic factors associated with full childhood vaccination in Bangladesh, 2014. International Journal of Infectious Diseases 2018; 69: 35-40

39. Nath B, Singh JV, Awasthi S, Bhushan V, Kumar $V$, Singh SK. A study on determinants of immunization coverage among 12-23 months old children in urban slums of Lucknow district, India. Indian J Med Sci. 2007; 61:598-606. 